\title{
Lentiviral-Mediated Delivery of Mutant Huntingtin in the Striatum of Rats Induces a Selective Neuropathology Modulated by Polyglutamine Repeat Size, Huntingtin Expression Levels, and Protein Length
}

\author{
Luis Pereira de Almeida,, ${ }^{1,2}$ Christopher A. Ross, ${ }^{3}$ Diana Zala, ${ }^{1,4}$ Patrick Aebischer, ${ }^{1,4}$ and Nicole Déglon ${ }^{1,4}$ \\ ${ }^{1}$ Division of Surgical Research and Gene Therapy Center, Lausanne University Medical School, 1011 Lausanne, \\ Switzerland, 2Laboratory of Pharmaceutical Technology, Faculty of Pharmacy and Center for Neuroscience, University of \\ Coimbra, 3000 Coimbra, Portugal, ${ }^{3}$ Division of Neurobiology, Departments of Psychiatry and Neuroscience, Johns \\ Hopkins University School of Medicine, Baltimore, Maryland 21205-2196, and 4 Swiss Federal Institute of Technology \\ Lausanne, 1015 Lausanne, Switzerland
}

\begin{abstract}
A new strategy based on lentiviral-mediated delivery of mutant huntingtin (htt) was used to create a genetic model of Huntington's disease (HD) in rats and to assess the relative contribution of polyglutamine (CAG) repeat size, htt expression levels, and protein length on the onset and specificity of the pathology. Lentiviral vectors coding for the first 171, 853, and 1520 amino acids of wild-type (19 CAG) or mutant htt (44, 66, and $82 \mathrm{CAG})$ driven by either the phosphoglycerate kinase 1 (PGK) or the cytomegalovirus (CMV) promoters were injected in rat striatum. A progressive pathology characterized by sequential appearance of ubiquitinated htt aggregates, loss of dopamine- and cAMP-regulated phosphoprotein of $32 \mathrm{kDa}$ staining, and cell death was observed over 6 months with mutant htt. Earlier onset and more severe pathology occurred with shorter frag-
\end{abstract}

ments, longer CAG repeats, and higher expression levels. Interestingly, the aggregates were predominantly located in the nucleus of PGK-htt171-injected rats, whereas they were present in both the nucleus and processes of CMV-htt171injected animals expressing lower transgene levels. Finally, a selective sparing of interneurons was observed in animals injected with vectors expressing mutant htt. These data demonstrate that lentiviral-mediated expression of mutant htt provides a robust in vivo genetic model for selective neural degeneration that will facilitate future studies on the pathogenesis of cell death and experimental therapeutics for HD.

Key words: Huntington's disease; genetic model; huntingtin; lentiviral vector; gene delivery; rat
Huntington's disease (HD) is caused by the expansion of a CAG trinucleotide within the coding region of the huntingtin (htt) gene (Huntington's Disease Collaborative Research Group, 1993). The hallmark features of HD are cognitive impairment, psychiatric disturbances, and motor disability irreversibly progressing to death 10-20 years after the onset of the symptoms (Vonsattel and DiFiglia, 1998). Despite the widespread expression of htt, the first affected region is the striatum, and, at a later stage of the disease, other brain areas such as the cerebral cortex are affected.

To gain insight into the molecular steps mediating neurotoxicity, genetic models of HD have been developed. Genomic DNA or cDNAs coding for truncated or full-length mutant huntingtin proteins under the control of endogenous or heterologous promoters have been used to produce transgenic or knock-in mice

Received Nov. 29, 2001; revised Feb. 11, 2002; accepted Feb. 12, 2002.

This work was supported in part by the Swiss National Science Foundation, the Association Française contre les Myopathies (N.D.), National Institute of Neurological Disorders and Stroke Grants 16375 and 38144, and the Huntington's Disease Society of America and the Huntington's Disease Foundation (C.A.R.). L.P.d.A. was supported by Portuguese Foundation for Science and Technology Grant BD 9469/96 (Praxis XXI program). We thank Xiao-Jiang Li, Lesley Jones, Paul Greengard, and Hugh C. Hemmings for generous gifts of antibodies and Jillian K. Cooper for the huntingtin expressing vectors. We also thank Albert Spicher, Yvan Arsenijevic, Fabienne Pidoux, Maria Rey, and Christel Sadeghi for contributions to this study and Etienne Régulier for critical reading of this manuscript.

Correspondence should be addressed to Dr. Nicole Déglon, Institute of Neuroscience, Swiss Federal Institute of Technology Lausanne, building SG-AAI, 1015 Lausanne, Switzerland. E-mail: nicole.deglon@epfl.ch.

Copyright (C) 2002 Society for Neuroscience $0270-6474 / 02 / 223473-11 \$ 15.00 / 0$
(Mangiarini et al., 1996; White et al., 1997; Reddy et al., 1998; Hodgson et al., 1999; Schilling et al., 1999; Shelbourne et al., 1999; Wheeler et al., 1999; Yamamoto et al., 2000; Lin et al., 2001). The severity of the pathology varies among these animals, but neurological phenotypes reminiscent of early $\mathrm{HD}$, including tremor, seizure, motor deficits, decreased brain weight, alterations of neurotransmitter receptor levels, nuclear inclusions, and astrogliosis were reported. Interestingly, reproducible and substantial loss of spiny medium neurons were not observed, even in transgenic mice expressing full-length htt (Hodgson et al., 1999; Reddy et al., 1999a). Moreover, side effects attributable to the widespread overexpression of htt and premature death not associated with the striatal pathology were reported (Mangiarini et al., 1996; Hurlbert et al., 1999; Reddy et al., 1999a,b).

We have therefore investigated whether lentiviral-mediated delivery of mutant htt can be used to address some of these issues and to create a genetic model of HD in rats. The potential use of viral-based gene transfer to generate animal models has been established by Senut et al. (2000) with an adeno-associated vector expressing expanded CAG repeats fused to the green fluorescent protein. Poly $(\mathrm{Q})$-dependent degeneration was observed in the striatum of rats, but the specificity of the pathology was not evaluated. Importantly, viral-mediated delivery of mutant htt has not been used to develop animal models of HD. In this context, lentiviral vectors are particularly suitable because of their large cloning capacity and high transduction efficiency. Previous studies 
have demonstrated that vesicular stomatitis virus G-proteinpseudotyped lentiviral vectors have a strong neurotropism and lead to long-term and robust transgene expression (Naldini et al., 1996; Blömer et al., 1997; Naldini, 1998; de Almeida et al., 2001). The present strategy holds various advantages over transgenic mice. Genetic models based on multiple variations of the transgene being expressed can be created in a short period. High transgene expression levels can be reached with lentiviral vectors, an important feature to exacerbate the disease process and to induce neuronal degeneration but avoiding side effects associated with a widespread overexpression of mutant huntingtin (Naldini et al., 1996; Déglon et al., 2000; Kordower et al., 2000). Regulated expression systems allowing gene-dosing experiments are available (Kafri et al., 2000). The specificity of the neuropathology can be assessed by targeting well defined brain regions. Finally, models can be established in different mammalian species, thereby providing an opportunity to conduct studies in nonhuman primates.

We have therefore cloned the cDNAs coding for the first 171, 853, and 1520 amino acids of huntingtin protein with 19 (wild type), 44, 66, and $82 \mathrm{CAG}$ repeats (mutant) in transfer vectors with cytomegalovirus (CMV) or mouse phosphoglycerate kinase 1 (PGK) internal promoters. The viruses expressing wild-type or mutant huntingtin were injected in the right and left striata of adult Wistar rats, respectively. A time course study was performed over 24 weeks to measure the appearance of nuclear inclusions, loss of neuronal markers, and subsequent cell death of GABAergic neurons as well as the susceptibility of choline acetyltransferase (ChAT) and NADPH diaphorase (NADPH-d) interneurons after lentiviral injection.

\section{MATERIALS AND METHODS}

\section{Lentiviral vector production}

Human huntingtin cDNAs coding for the first 171, 583, and 1520 amino acids of the protein with 19, 44, 66, or 82 CAG repeats (Cooper et al., 1998; Schilling et al., 2001) were cloned in self-inactivating transfer vector (SIN) containing the woodchuck hepatitis virus postregulatory element (W) (Déglon et al., 2000). Mouse PGK and CMV were used as internal promoters. The viral particles were produced by transient calcium phosphate transfection of $3 \times 10^{6}$ human embryonic kidney 293T cells (Ory et al., 1996) plated in $10 \mathrm{~cm}$ Petri dishes (Falcon; Becton Dickinson, Rutherford, NJ) with $13 \mu \mathrm{g}$ of pCMVDR-8.92 packaging construct, $3.75 \mu \mathrm{g}$ of pMD.G, $3 \mu \mathrm{g}$ of pRSV-Rev, and $13 \mu \mathrm{g}$ of SIN-WPGK or SIN-W-CMV transfer vectors, as previously described (Hottinger et al., 2000). Forty-eight hours later, the supernatants were collected, filtered, and concentrated by ultracentrifugation, and the particle content was determined by p24 antigen ELISA (PerkinElmer Life Sciences, Boston, MA). For the in vivo experiments, the different batches of viruses were matched for particle content and used at 200,000 ng of $\mathrm{p} 24 / \mathrm{ml}$.

\section{Western blot analysis}

293 T cells were plated in six-well tissue culture dishes (Becton Dickinson) at a density of 150,000 cells per well. The cells were infected with the lentiviral vectors matched for particle content (600 ng of p24 antigen/ well). Twelve hours later, the medium was removed and replaced with fresh DMEM containing 10\% fetal calf serum, 2 mM L-glutamine, 4.5 $\mathrm{gm} / 1$ glucose, $100 \mathrm{U} / \mathrm{ml}$ penicillin, and $100 \mathrm{U} / \mathrm{ml}$ streptomycin. Three days after infection, the cells were washed in $0.05 \mathrm{M}$ PBS, harvested, and lysed in $0.05 \mathrm{M} \mathrm{KHPO}_{4}, \mathrm{pH} 7.8$, and $0.03 \%$ Triton X-100 (Sigma, St. Louis, MO), with a mixture of protease inhibitors (pronase, thermolysin, chymotrypsin, trypsin, and papain; Roche Pharma, Reinach, Switzerland). The cell lysates were centrifuged at $4^{\circ} \mathrm{C}$ for $30 \mathrm{~min}$ at $10,000 \times g$. Protein concentration was determined with the bicinchoninic acid assay (Pierce, Rockford, IL). Sixty micrograms of the protein extracts were analyzed on 7.5 or $10 \%$ SDS-polyacrylamide gels. The proteins were transferred to nitrocellulose membranes (Bio-Rad, Hercules, CA) using a buffer of $192 \mathrm{~mm}$ Tris- $\mathrm{HCl}, 25 \mathrm{~mm}$ glycine, and $10 \%$ methanol. The blots were blocked in $10 \%$ normal goat serum (NGS; Dako, Glostrup, Denmark) in PBS for $2 \mathrm{hr}$ at room temperature (RT), followed by incubation for $48 \mathrm{hr}$ with a 1:4000 dilution of the EM48 anti-huntingtin antibody (kindly provided by Dr. X. J. Li, Emory University School of Medicine, Atlanta, GA; Li et al., 1999). Blots were washed for $2 \mathrm{hr}$ and incubated with a biotinylated goat anti-rabbit antibody (1:4000; Vector Laboratories, Burlingame, CA) for $1.5 \mathrm{hr}$ at RT. After a $1 \mathrm{hr}$ wash, the blot was incubated with avidin-peroxidase reagent [Vectastain avidinbiotin complex (ABC) kit; Vector Laboratories] for $30 \mathrm{~min}$ at RT. The detection was performed using an Enhanced Chemiluminescence Plus kit (Amersham Biosciences, Uppsala, Sweden).

\section{Animals}

Adult female Wistar rats (Iffa-Credo) weighing 200 gm were used. The animals were housed in a controlled temperature room that was maintained on a $12 \mathrm{hr}$ light/dark cycle. Food and water were available ad libitum. The experiments were performed out in accordance with the European Community Council directive 86/609/EEC for care and use of laboratory animals.

\section{Injection of the lentiviruses}

The stereotaxic injections (David Kopf Instruments, Tujunga, CA; $n=$ 3 per group) were performed under pentobarbital anesthesia $(45 \mathrm{mg} / \mathrm{kg}$, i.p.) using a syringe (Hamilton, Reno, NV) with a 30 gauge blunt-tip needle. Lentiviral vectors expressing the wild-type or mutant htt were injected in the left or the right striatum, respectively. The animal received two $4 \mu \mathrm{l}$ injections of lentiviral vectors in each side at the following coordinates: 1.0 and 0.0 rostral to bregma, 3.0 and 3.3 lateral to midline, and 5.0 ventral from the skull surface, with the mouth bar set at 3.3. The viruses were injected at $0.2 \mu \mathrm{l} / \mathrm{min}$ by means of an automatic injector (Stoelting Co.), and the needle was left in place for $5 \mathrm{~min}$. The skin was closed using a 6-0 Vicryl suture (Ethicon; Johnson \& Johnson, Brussels, Belgium). Three animals were killed, and the brains processed for immunohistochemistry $1,2,4,8$, and 12 weeks after injection. A long-term study was performed with lentivirus coding for htt171, htt853, and htt1520 ( $n=3$ per group). In these animals, a single $4 \mu$ l dose of lentivirus was injected 0.5 rostral to bregma, 3.0 lateral to midline, and 5.0 ventral from the skull surface, with the mouth bar set at 3.3.

\section{Histological processing}

Tissue preparation. At the time of killing, the animals were anesthetized with a sodium pentobarbital overdose, transcardially perfused, post-fixed in $4 \%$ paraformaldehyde for $24 \mathrm{hr}$, and finally cryoprotected in $25 \%$ sucrose and $0.1 \mathrm{M}$ phosphate buffer for $48-72 \mathrm{hr}$. The brains were frozen in dry ice, and coronal sections were cut on a sliding microtome cryostat (Cryocut 1800; Leica Microsystems, Nussloch, Germany) at a temperature of $-20^{\circ} \mathrm{C}$ and a thickness of $25 \mu \mathrm{m}$. Free-floating sections throughout the entire striatum were collected in PBS containing $0.12 \mu \mathrm{M}$ sodium azide (Costar, Cambridge, MA). The 48 -well trays were stored at $4{ }^{\circ} \mathrm{C}$ until immunohistochemical processing.

Primary antibodies. The following primary antibodies were used: affinity-purified rabbit polyclonal antibody 675 (Ab675) recognizing the first 17 amino acids of wild-type and mutant huntingtin (kindly provided by Dr. Jones, University of Wales, Cardiff, UK; Wilkinson et al., 1999); the rabbit polyclonal EM48 antibody raised against the first 256 amino acids of a huntingtin protein lacking the polyglutamine and polyproline tracts (Li et al., 1999); a rabbit polyclonal anti-ubiquitin antibody (Dako); a mouse monoclonal antibody recognizing the dopamine- and CAMPregulated phosphoprotein of $32 \mathrm{kDa}$ (DARPP-32; a generous gift from Drs. P. Greengard and H. C. Hemmings, Rockefeller University, New York, NY); a rabbit polyclonal anti-DARPP-32 antibody (Chemicon, Temecula, CA); and a mouse monoclonal antibody recognizing the ChAT antibody (Roche Pharma).

Immunohistochemical procedure. The immunohistochemical procedure was initiated by endogenous peroxidase quenching with a $30 \mathrm{~min}$ incubation at $37^{\circ} \mathrm{C}$ in a PBS solution containing $0.1 \%$ diphenylhydrazine. Free-floating sections were incubated at RT for $1 \mathrm{hr}$ in $0.1 \mathrm{M}$ PBS containing $10 \%$ NGS (Dako), followed by a reaction with the respective antibodies: EM48 (1:5000, 2 d RT), ubiquitin [1:1000; overnight $(\mathrm{O} / \mathrm{N})$ $\left.4^{\circ} \mathrm{C}\right]$, mouse DARPP-32 $\left(1: 50,000, \mathrm{O} / \mathrm{N} 4^{\circ} \mathrm{C}\right)$, and ChAT $(1: 300, \mathrm{O} / \mathrm{N}$ $\left.4^{\circ} \mathrm{C}\right)$, diluted in PBS and 5\% NGS solution. After three washings, the sections were incubated with the corresponding biotinylated secondary antibody (1:200; Vector Laboratories) diluted in PBS and 1\% NGS for 2 $\mathrm{hr}$ at RT, and bound antibody was visualized by using the Vectastain $\mathrm{ABC}$ kit, with 3,3'-diaminobenzidine tetrahydrochloride (DAB metal 
concentrate; Pierce) as substrate. The sections were mounted, dehydrated by passing twice through ethanol and toluol, and coverslipped with Merckoglas. Triple stainings for DARPP-32, ChAT, and NADPH-d or for huntingtin (EM48 Ab), ChAT, and NADPH-d were performed by successive immunostainings with peroxidase substrates, DAB metal concentrate (brown), and 3-amino-9-ethylcarbazole (red peroxidase substrate kit; Vector Laboratories) and enzymatic staining for NADPH-d (blue). The nuclear localization of huntingtin was investigated on sections double-stained for huntingtin (EM48 Ab) and 4',6-diamidino-2phenylindole, dihydrochloride (DAPI). Huntingtin immunohistochemistry was done as previously described, and a tyramide substrate was used for the detection (PerkinElmer Life Sciences). To avoid overstaining of the nucleus, which could mask the dense nuclear aggregates, a short development time was used. DAPI staining was performed as indicated by the supplier (Molecular Probes Europe, Leiden, The Netherlands). Degenerating neurons were stained with the anionic fluorescein derivative Fluoro-Jade B (Schmued and Hopkins, 2000). The sections were first washed in water and then mounted on sylanized glass slides, dehydrated, and stained according to the supplier's manual (Schmued et al., 1997). Finally, the enzymatic staining for NADPH-d was performed as previously described (Ellison et al., 1987).

\section{Cell counting and evaluation of the volume of DARPP-32-depleted region}

The number of huntingtin aggregates, the DARPP-32-depleted volume, and the estimation of ChAT and NADPH-d-immunoreactive neurons in the DARPP-32-depleted region were determined with an automatic image analysis system (SIS-Soft imaging system coupled to a ZX60 microscope, Olympus; Munster, Germany) on six sections separated by $400 \mu \mathrm{m}$. The EM48-positive nuclei were counted at a magnification of $4 \times$, and the total number of aggregates per brain was obtained by multiplying the counts by 16 . The area of the striatum showing a loss of DARPP-32 staining was measured for each animal with an operatorindependent macro. The volume was then estimated with the following formula: volume $=d\left(a_{1}+a_{2}+a_{3} \ldots\right)$, where $d$ is distance between serial sections $(400 \mu \mathrm{m})$, and $a_{1}, a_{2}, a_{3} \ldots$ are DARPP-32-depleted areas for individual serial sections (Reynolds et al., 1998). Triple-stained sections were used to determine the number of ChAT- and NADPH-d-positive neurons in the DARPP-32-depleted area of htt171-82Q-injected animals. The counts were performed at a magnification of $20 \times$, and the values were expressed as percentages of neurons on the contralateral side.

\section{Data analyses}

Data are expressed as mean \pm SEM and were evaluated by ANOVA followed by a Scheffe's protected least significant difference post hoc test (StatView 4.0, version 3.2.6; Aladdin Systems). The significance level was set at $p<0.05$.

\section{RESULTS}

\section{Lentiviral-mediated expression of truncated human huntingtin}

A Western blot analysis was performed to test the different lentiviral vectors (Fig. $1 A, B$ ). Figure $1 B$ shows that huntingtin fragments with the predicted molecular weights are produced in infected 293T cells and that there is no significant difference in the expression levels. The capacity to overexpress human huntingtin protein in a large area of the striatum of adult rats was then assessed with the htt171-19Q and htt171-82Q vectors (Fig. $1 C-E)$. One week after lentivirus injection, both wild-type and mutant proteins were detected 1-2 $\mathrm{mm}$ from the injection site (Fig. $1 C, D$ ). A gradual decrease in the intensity of the staining was obtained as the distance from the injection site increased. This gradient of expression probably reflects the progressive decrease in transduction efficiency and as a consequence of the number of integrated transgenes per cell, as indicated by in situ hybridization experiments (data not shown). Sustained expression of the transgene was observed 3 months after injection of the virus (Fig. 1E).
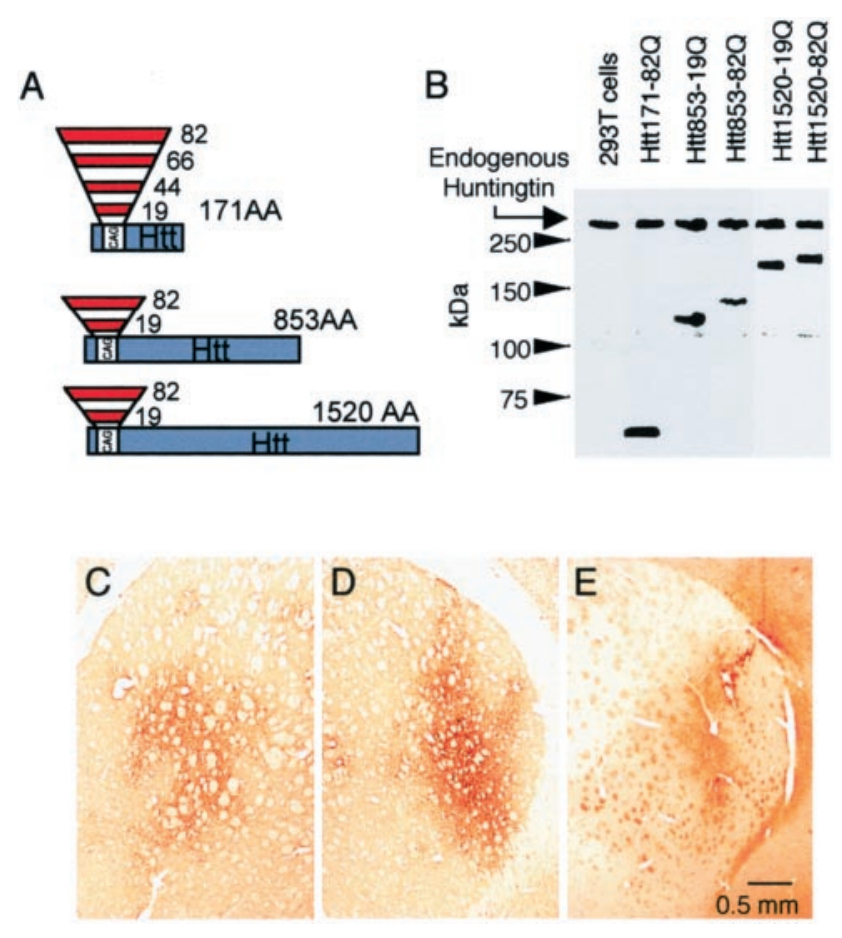

Figure 1. A, Schematic representation of the lentiviral constructs used in this study. cDNAs coding for the first 171,853 , and 1520 amino acids of human huntingtin with $19,44,66$, or 82 CAG repeats were cloned in the SIN-W transfer vector. $B$, Western blot analysis, using the EM-48 antibody showing that huntingtin fragments of the expected molecular weights are produced in human embryonic kidney $293 \mathrm{~T}$ cells infected with the corresponding lentiviral vectors. $C-E$, Photomicrographs of striatal sections immunostained with the Ab675 antibody recognizing the $\mathrm{N}$-terminal part of huntingtin. One week after injection, both wild-type (htt171-19Q; C) and mutant (htt171-82Q; D) huntingtin fragments are overexpressed in a large area of the striatum. $E$, Sustained expression of the transgene was observed 12 weeks after injection.

\section{Injection of the htt171-82Q vector induces HD neuropathology in the rat striatum}

To analyze the progressive morphological changes associated with the intrastriatal expression of htt171-82Q, rats were killed 1 , $2,4,8$, and 12 weeks after lentiviral injection. The formation of huntingtin nuclear aggregates, a hallmark of the disease (Paulson, 2000), was used as a first marker to monitor the appearance of pathology (Fig. 2A-E). None of the htt171-19Q-injected striata were stained with the EM48 antibody (Fig. 2D). In contrast, the expression of mutant htt171-82Q protein induced the formation of huntingtin aggregates already detected 1 week after viral injection (Fig. 2A). Although, huntingtin immunoreactivity is generally detected in the whole nucleus, dense staining is present in large spherical nuclear inclusions (NIs; Fig. $2 K$ ). Double staining with EM48 and DAPI confirmed that most of the aggregates are present in the cell nucleus (Fig. $2 L$ ). The inclusions progressively accumulate over the first 4 weeks, and their number remains constant thereafter (Fig. 2B,C,E). In agreement with previous reports (Lin et al., 2001), we observed that these inclusions are ubiquitinated as early as 2 weeks after lentivirus injection (Fig. 2M,N). Interestingly, 8 and 12 weeks after injection, the EM48 staining was no longer detectable in the immediate vicinity of the injection site, suggesting that progressive striatal degeneration had occurred (Fig. 2C). New inclusions, however, appear at 

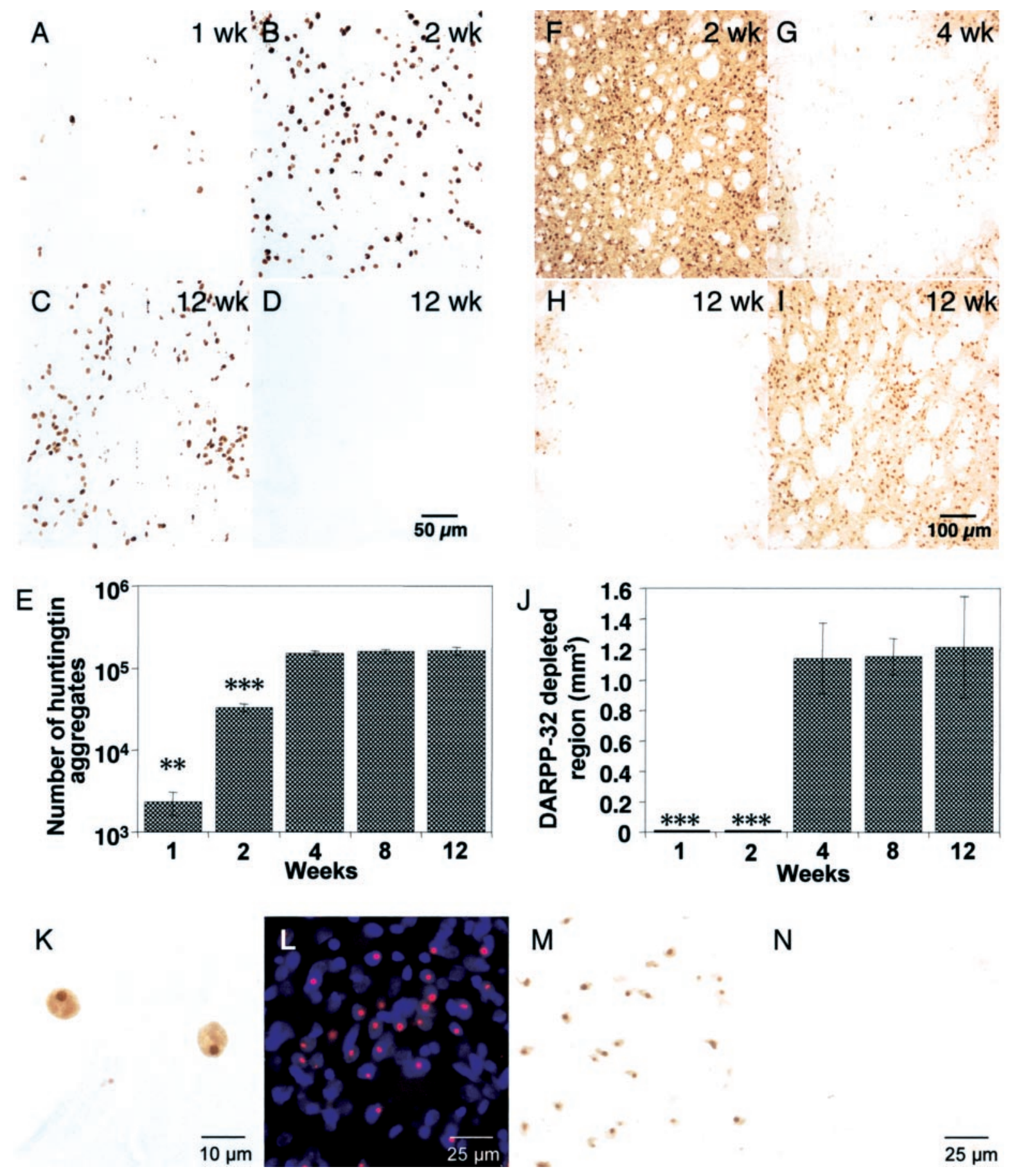

Figure 2. Time course analysis of the neuropathology in htt171-19Q- and htt171-82Q-infected rats. $A-C$, Huntingtin aggregates were first detected 1 week after injection of htt171-82Q and progressively accumulated during the 12 week study period. $D$, As expected, huntingtin inclusions were not identified with the EM48 antibody in the htt171-19Q-transduced hemisphere. E, Quantification of the number of cells containing huntingtin aggregates in the striatum of htt171-82Q-injected rats. ${ }^{* *} p<0.01 . F-H$, Evaluation of the neurotoxicity of wild-type and mutant huntingtin fragments on DARPP-32-stained striatal sections. $G$, Four weeks after infection, a drastic loss of DARPP-32-immunoreactive neurons was observed in the htt171-82Q-infected striatum, whereas overexpression of the wild-type protein (htt171-19Q; $I$ ) had no deleterious effect on DARPP-32 staining even at 3 months. $J$, Quantification of the DARPP-32-depleted region on the htt171-82Q-transduced striatal neurons. * $p<0.05 ;{ }^{* *} p<0.01 ; * * *<<0.001 . K$, EM48 staining showing an immunoreactive nucleus with neuronal intranuclear inclusions. $L$, DAPI and EM48 double staining showing that most of the htt aggregates are located in the nucleus of htt171-82Q-infected neurons and colocalized with ubiquitin $(M)$. $N$, Ubiquitin staining in htt171-19Q-injected rats.

the periphery of the lesion, resulting in an almost unchanged overall inclusion number.

To further investigate whether the overexpression of htt171$82 \mathrm{Q}$ is associated with neuronal dysfunction, striatal degenera- tion, or both, an immunohistochemical analysis was performed with the DARPP-32 antibody (Fig. $2 F-J$ ). This regulator of dopamine receptor signaling (Greengard et al., 1999) is expressed in $96 \%$ of the striatal medium-sized spiny neurons and is down- 


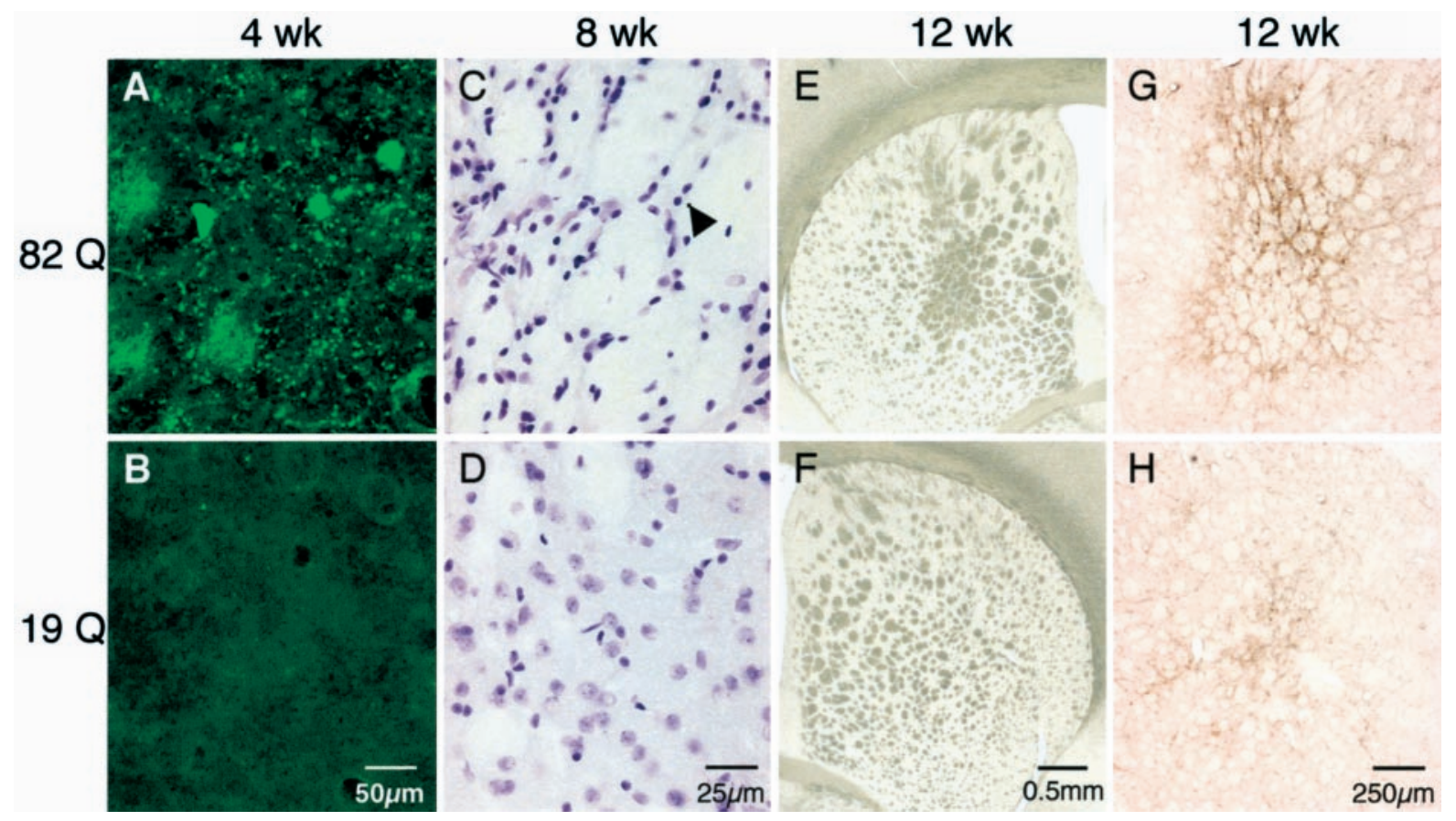

Figure 3. Progressive striatal degeneration in htt171-82Q-injected rats. $A$, The first indication of striatal degeneration was observed at 4 weeks on Fluoro-Jade B-stained sections. $C$, At 8 weeks, pyknotic nuclei (arrowhead) were visible on cresyl violet-stained sections. $E$, Coalescence of the internal capsule of the striatum was observed at 12 weeks on a bright-field photomicrograph. In contrast, no signs of degeneration were observed with the wild-type huntingtin fragment $(B, D, F, H)$. Finally, robust GFAP staining was observed 3 months after injection in mutant htt $(G)$ compared with wild-type htt $(H)$.

regulated in HD transgenic mice (Ouimet et al., 1998; Bibb et al., 2000; Luthi-Carter et al., 2000; van Dellen et al., 2000). A loss of DARPP-32 immunoreactivity in the striatum of htt171-82Qinjected animals was observed at 4 weeks (Fig. $2 G$ ), a time point that corresponds to the peak accumulation of NIs $(152,700 \pm$ 8140 N Is per animal). In animals injected with the htt171-82Q lentivirus, a DARPP-32-depleted region of $1.14 \pm 0.23 \mathrm{~mm}^{3}$ was measured, whereas no loss of DARPP-32 staining was detected with the htt171-19Q fragment (Fig. 2I,J). Similar results were obtained with the neuronal marker NeuN (neuronal nuclei) (data not shown). To assess whether the loss of DARPP-32 and NeuN staining was attributable to neuronal dysfunction or cell death, we first used the Fluoro-Jade B dye that stains preferentially degenerating neurons (Schmued et al., 1997; Schmued and Hopkins, 2000). Scattered fluorescent neurons as well as punctate staining were visible 4-12 weeks after the injection of htt171-82Q (Fig. $3 A$ ). No staining was detected in htt171-19Q-transduced hemispheres (Fig. $3 B$ ). Furthermore, an increased number of shrunken hyperchromatic nuclei were observed over time on cresyl violetstained sections (Fig. 3C, arrowhead). Condensation of the internal capsule attributable to striatal tissue shrinkage was also clearly visible on a bright-field image of the striatum at 12 weeks (Fig. 3E). Finally, the expression of glial fibrillary acidic protein (GFAP) was analyzed as an indicator of reactive astrogliosis characteristic of HD. Twelve weeks after injection, robust GFAP staining was observed around the injection site of htt171-82Qinjected rats, whereas the GFAP staining was mild in htt171-91Qinjected animals (Fig. 2G,H). Altogether these data indicate that in Htt171-82Q-injected rats, the appearance of nuclear inclusions precedes neuronal dysfunction and that the phenotype progresses over 3 months, leading to a drastic degeneration of striatal neurons associated with astrogliosis.

\section{Specificity of toxicity in htt171-82Q-injected rats}

HD is characterized by selective degeneration of GABAergic neurons, with a relative sparing of ChAT and NADPH-d interneurons, at least in the early stages of the disease (Vonsattel and DiFiglia, 1998). Triple staining for DARPP-32, ChAT, and NADPH-d was therefore performed to assess the specificity of the pathology in htt171-82Q-injected rats (Fig. 4A,B). The numbers of ChAT- and NADPH-d-positive interneurons in the DARPP-32-depleted area (DARPP-32-negative) were counted and expressed as percentages of neurons on the contralateral side. On average, $47.4 \pm 8.6 \%$ of ChAT-positive and $80.3 \pm 5.1 \%$ of NADPH-d-positive neurons were preserved 3 months after injection (Fig. $4 F$ ). Double staining with EM48 and ChAT or NADPH-d was performed to demonstrate that this was not the result of resistance to lentiviral infection (Fig. $4 C-E$ ).

\section{The neurodegenerative effect of htt171-82Q is dose-dependent}

The pathology obtained in this study is more severe than what has been described in transgenic mice expressing the htt171-82Q fragment (Schilling et al., 1999). This discrepancy is potentially related to differences in transgene expression levels or species specificity. To exclude the latter hypothesis, htt171-19Q and $-82 \mathrm{Q}$ lentiviruses were injected in the striatum of mice. Neuropathology similar to what was described in rats was obtained (data not shown). To test the dose-dependent hypothesis, the htt171-82Q cDNA was cloned in an SIN-W transfer vector containing the CMV promoter. We have previously demonstrated that this promoter is weaker than the mouse PGK promoter in the striatum of rats (de Almeida et al., 2001). As shown in Figure 5, the DARPP-32-depleted area was smaller in CMV-htt171-injected animals compared with the PGK-htt171-injected cohort. The 

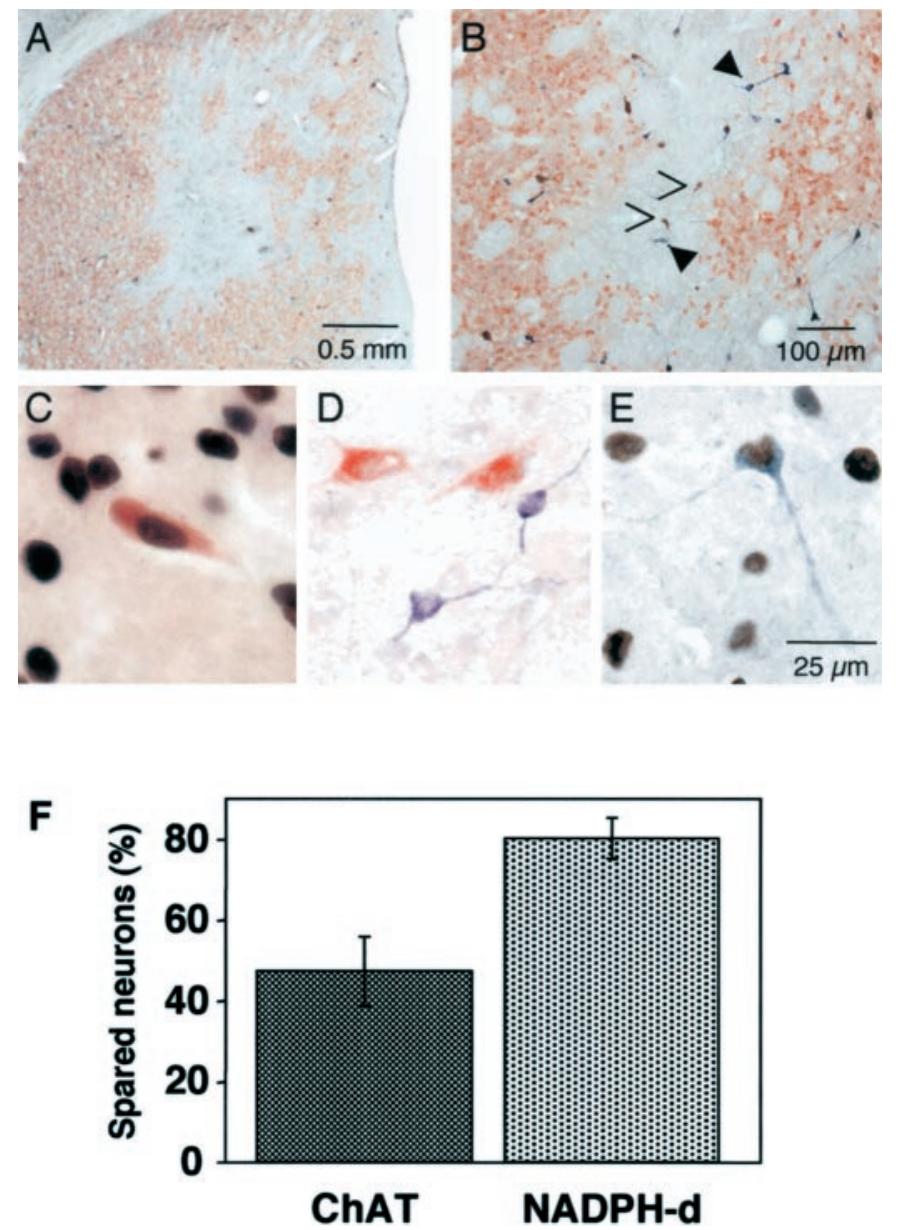

Figure 4. Specificity of the striatal toxicity in htt171-82Q-injected rats. Low-power $(A)$ and high-power $(B)$ photomicrographs of a striatal section triple-stained for DARPP-32 (red), ChAT (brown), and NADPH-d (blue) show that 12 weeks after the injection of htt171-82Q, ChATpositive (arrowhead) and NADPH-d-positive (open triangle) interneurons are still present at the center of the DARPP-32 depleted region. Double staining shows that ChAT-positive $(C, r e d)$ and NADPH-d-positive $(E$, blue) neurons are transduced and develop large neuronal intranuclear huntingtin aggregates (brown). D, Control, noninfected ChAT and NADPH-d neurons. $F$, Quantification of the data illustrating the selective sparing of ChAT and NADPH-d interneurons at 3 months.

accumulation of htt aggregates was also delayed in CMV-htt171injected animals ( 1 week, $2331 \pm 714$ PGK vs $2544 \pm 560 \mathrm{CMV}$; 2 weeks, 33,045 \pm 3661 vs $4027 \pm 1030$; 4 weeks, $152,736 \pm 8140$ vs $36,261 \pm 21,201 ; 8$ weeks, $159,136 \pm 10,328$ vs $16,293 \pm 12,210$; and 12 weeks, $163,200 \pm 16,819$ vs $107,056 \pm 16,994)$. Unexpectedly, the htt aggregates were distributed in both the nucleus and processes of CMV-htt171-injected animals (Fig. 6C,D), whereas they were predominantly located in the nucleus of PGK-htt171injected rats (Fig. 6A,B).

\section{The neuropathology correlates with CAG repeat length}

In HD patients, a clear correlation between polyglutamine length and disease severity has been reported (Duyao et al., 1993; Snell et al., 1993; Furtado et al., 1996). This observation was assessed with htt171 lentiviral constructs containing 19, 44, 66, and 82 CAG repeats. Aggregation of htt was evidenced 1 week after injection of htt171-82Q vector, whereas the appearance of nuclear inclusions was delayed by 1 and 3 weeks with the htt171-66Q and htt171-44Q vectors, respectively (Fig. 7A). A direct correlation

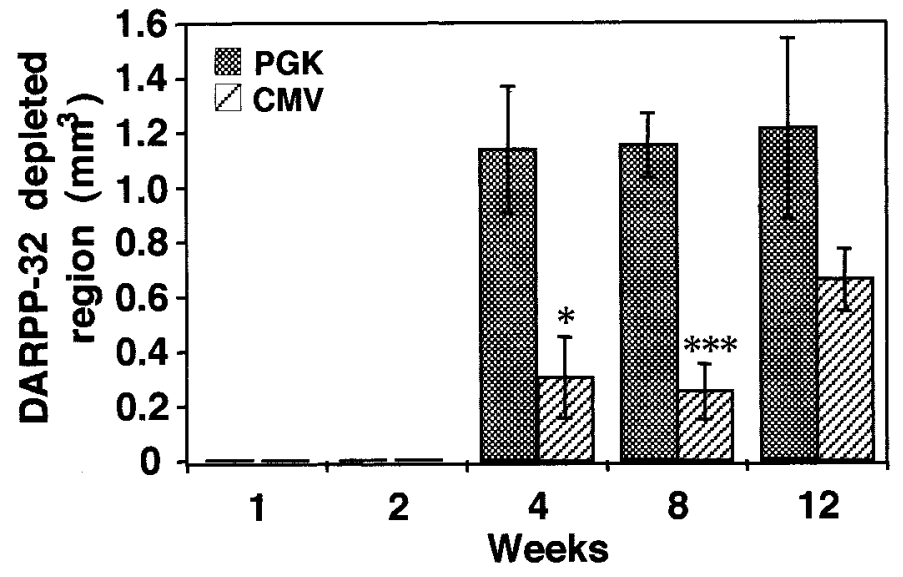

Figure 5. Impact of huntingtin expression levels on the severity of the pathology. The DARPP-32-depleted areas significantly decreased in CMV-htt171-81Q-injected animals compared with PGK-htt171-82Qinjected rats. ${ }^{*} p<0.05 ;{ }^{* * *} p<0.001$.

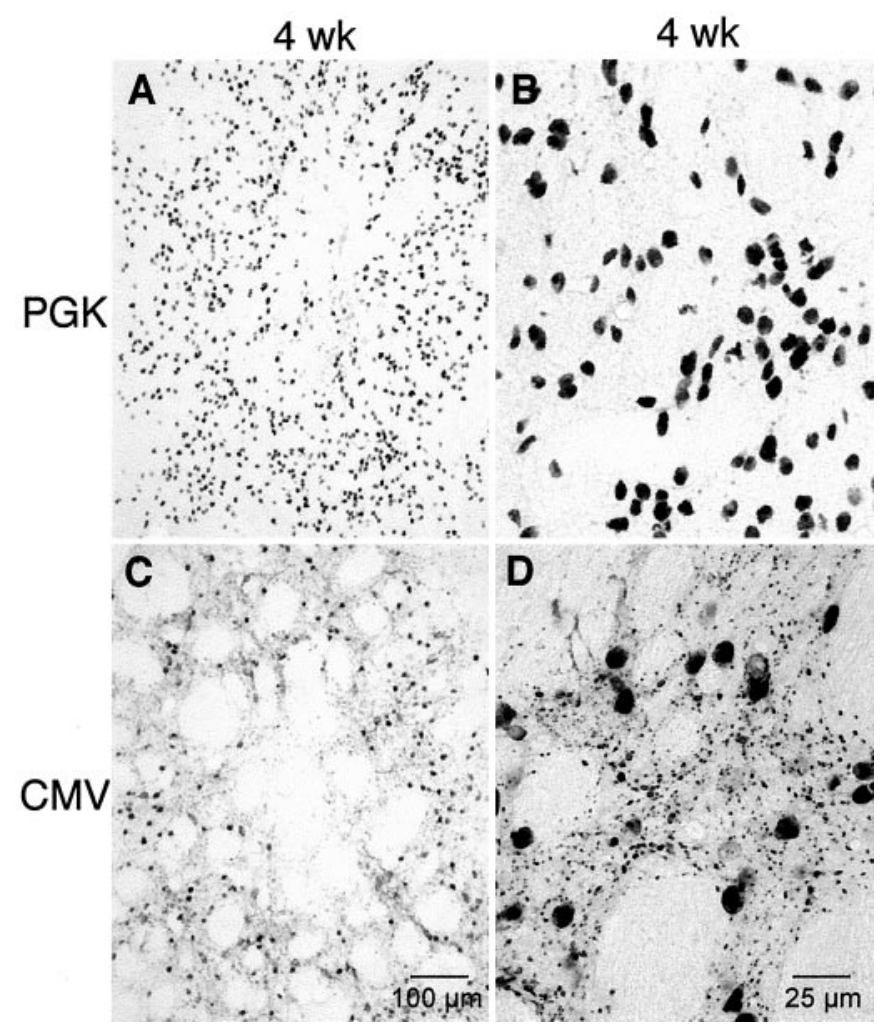

Figure 6. Impact of huntingtin expression levels on the formation of aggregates. We have previously shown that the CMV promoter leads to a reduced expression level in the rat brain compared with the PGK promoter. Decreasing the in vivo expression level of the Htt171-82Q fragment alters the subcellular localization of the huntingtin inclusions $(A-D)$. Low-magnification $(A)$ and high-magnification $(B)$ photomicrographs show that the EM48-immunoreactive aggregates in PGK-htt171$82 \mathrm{Q}$-injected animals are mainly restricted to the nucleus of infected neurons, whereas both nuclear and neuritic aggregates are observed in the CMV-htt171-82Q-injected animals $(C, D)$.

between the polyglutamine length and the number of aggregates was observed (Fig. 7B). A threshold effect was visible on DARPP32-stained sections, with an absence of pathology and huntingtin fragments containing up to $44 \mathrm{CAG}$ repeats (Fig. $8 \mathrm{~A}$ ). Moreover, 

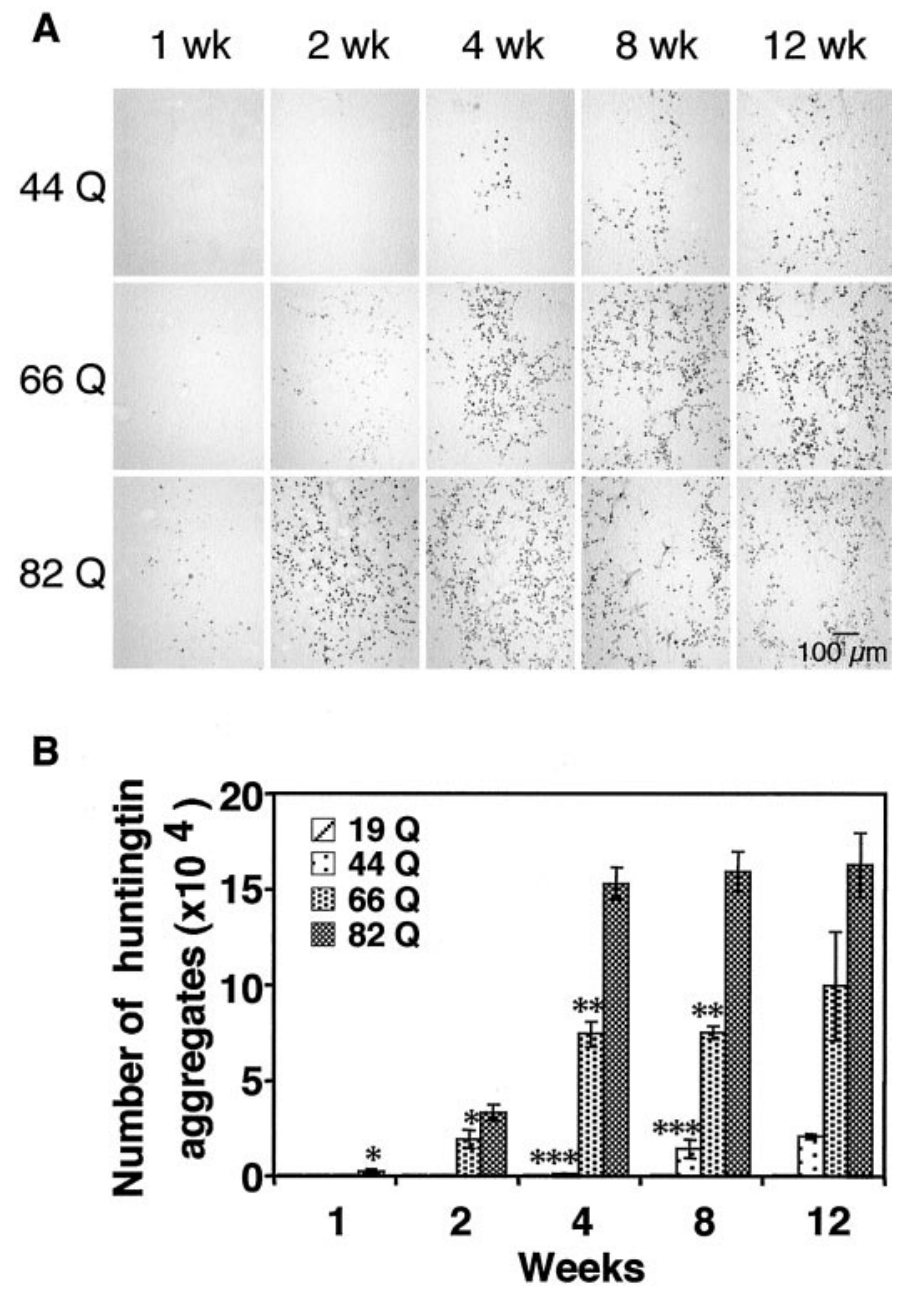

Figure 7. Impact of polyglutamine repeat size on the formation of huntingtin aggregates. $A$, Nuclear inclusions are first detected 4 weeks after injection of the htt171-44Q lentiviral vector and progressively accumulate over time. Increasing the CAG repeat size to 66 and 82 leads to an earlier appearance of aggregates and a significant increase in the number of nuclear inclusions. $B$, Quantification of the data showing the direct relationship between CAG repeat size and aggregate formation. ${ }^{*} p<$ $0.05 ; * *<<0.01 ; * * * p<0.001$.

the size of the DARPP-32-depleted region in htt171-66Q-injected animals was smaller compared with htt171-82Q rats (Fig. 8B).

\section{Mutant htt toxicity is inversely correlated with htt protein length}

A series of vectors expressing truncated huntingtin proteins with 171,853 , and 1520 amino acids and either 19 or 82 CAG repeats were produced to assess the impact of huntingtin protein length on the development of the neuropathology. In the animals expressing htt853-82Q or htt1520-82Q, the number of nuclear inclusions was decreased, whereas the frequency of neuropil aggregates was significantly augmented compared with htt171-82Q (Figs. 9, 10). The appearance of a DARPP-32-depleted region was also significantly delayed with the longer huntingtin fragments (853 and 1520 amino acids; Fig. 10). At 3 months after injection, a diffuse loss of DARPP-32 staining was observed with the 853-amino acid construct. At 6 months after injection, the DARPP-32-depleted region induced by the htt853-82Q injection was comparable with the one obtained with the htt171-82Q construct at 8 weeks. Finally, the longer htt1520-82Q construct had

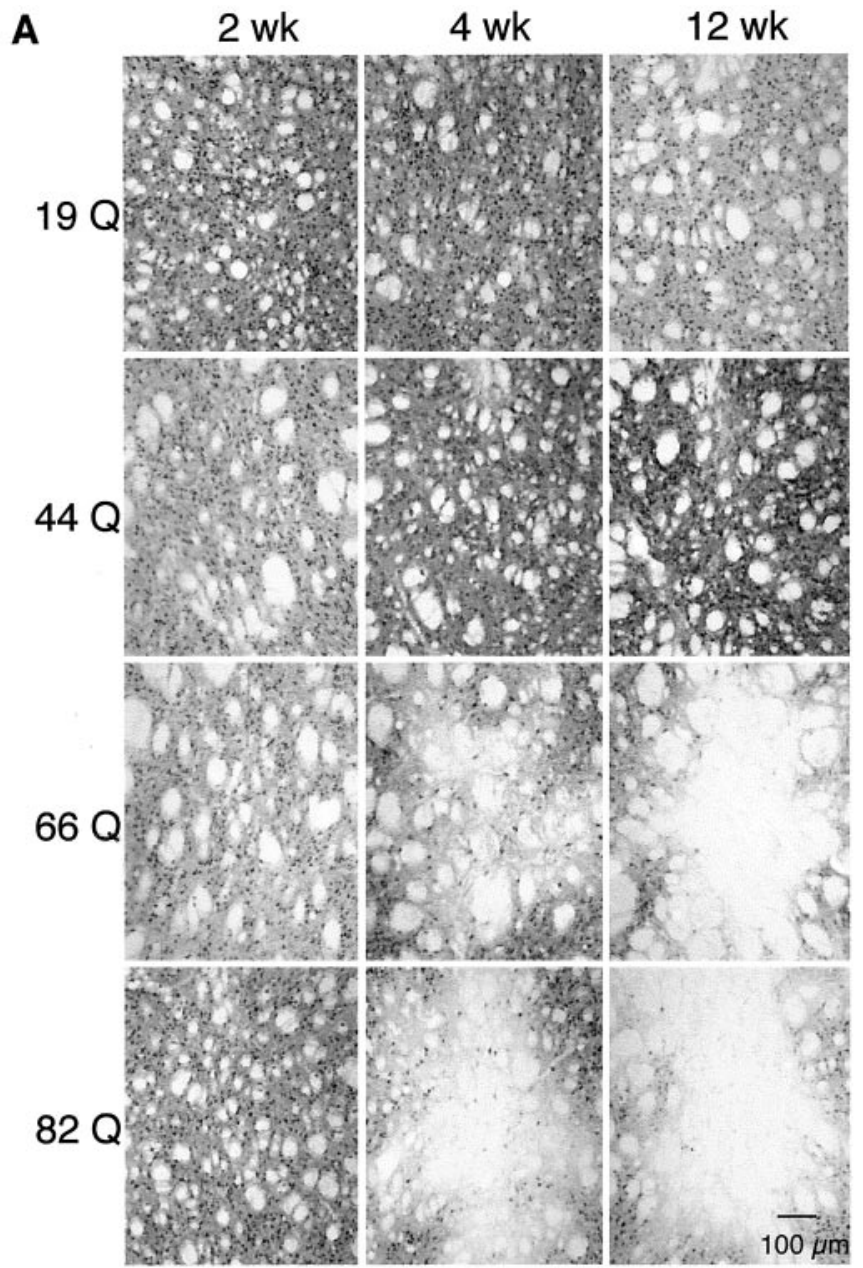

B

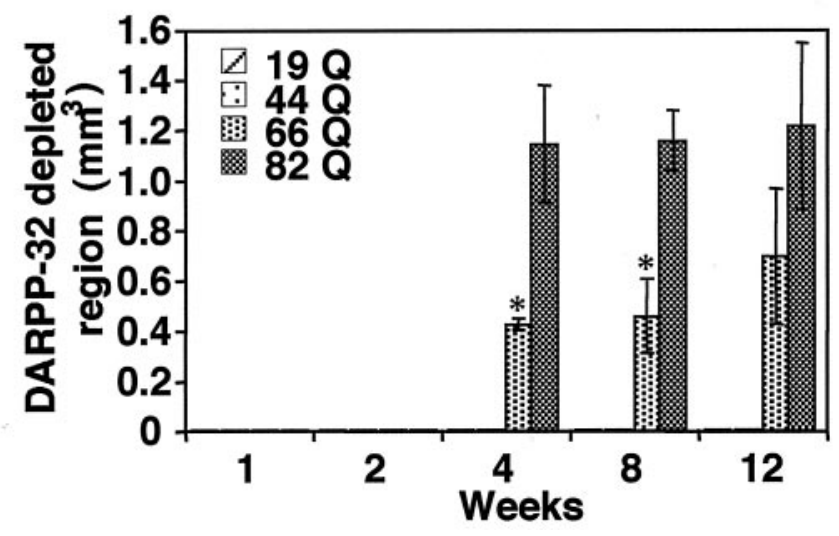

Figure 8. Influence of polyglutamine tract on the loss of DARPP-32 immunoreactivity. $A$, As expected, the overexpression of wild-type htt171 is not inducing a loss of DARPP-32 immunoreactivity. Interestingly, the DARPP-32 staining is also preserved in the htt171-44Q-injected animals, although huntingtin aggregates are first detected at 4 weeks in these animals. In the htt171-66Q-injected animals, the first indication of cellular dysfunction is observed at 4 weeks. Finally, a large DARPP-32-depleted region was present around the injection site in the htt171-82Q group. $B$, Quantification of the data showing the size of the DARPP-32-depleted region. ${ }^{*} p<0.05$. 


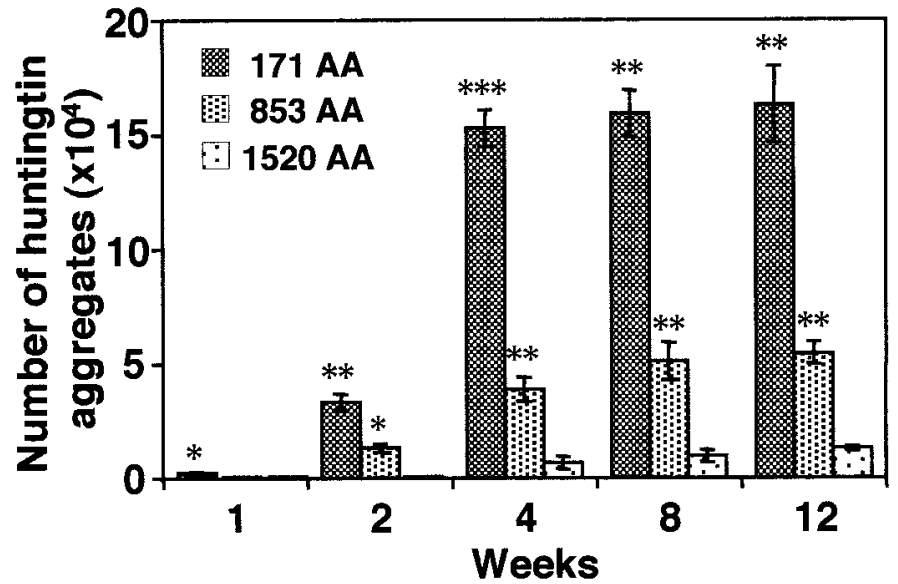

Figure 9. Impact of huntingtin protein length on the formation of aggregates. Increasing the huntingtin fragment size from 171 to 853 and 1520 amino acids significantly delays the appearance of neuronal aggregates. ${ }^{*} p<0.05 ; * * p<0.01 ; * * * p<0.001$.

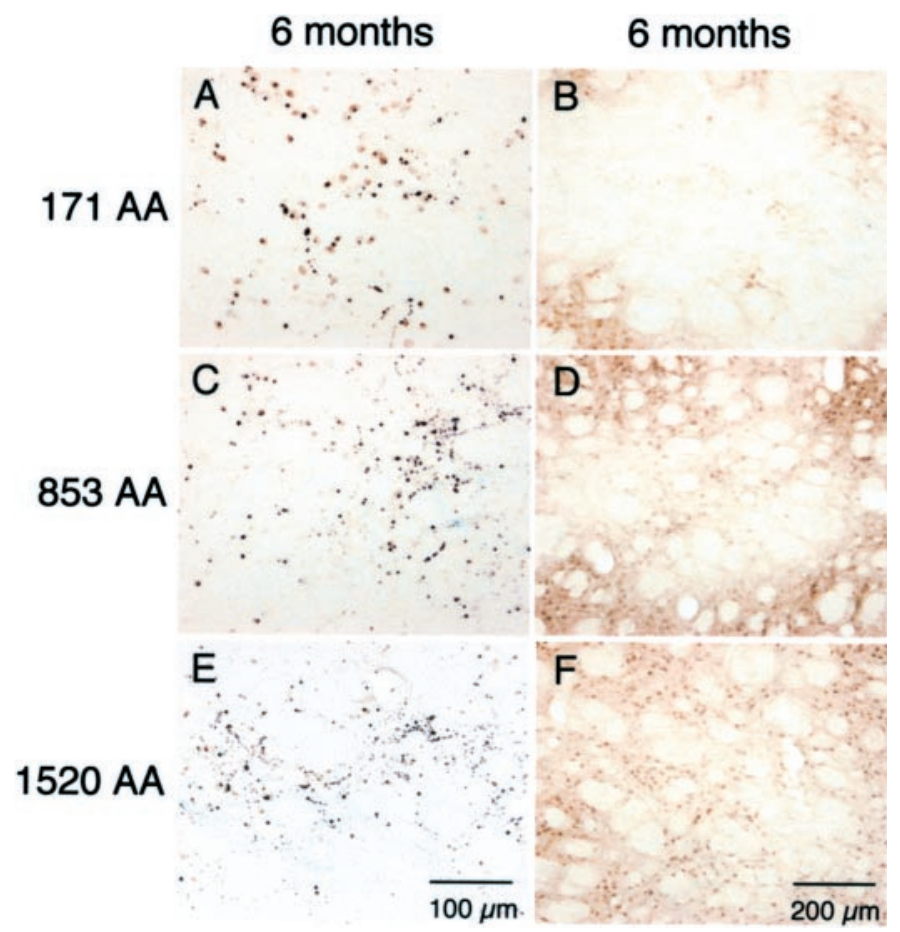

Figure 10. Striatal neuropathology 6 months after injection of lentiviral vectors coding for huntingtin fragments of various lengths. $A$, In htt17182Q-injected rats, EM48-positive nuclear inclusions are still present but are mainly located at the limit of the degenerating area, whereas aggregates are detected around the injection site with the longer huntingtin fragments $(C, E)$. Note that increasing the huntingtin fragment size modifies the subcellular localization of aggregates from nuclear to neuritic $(A, C, E) . B, D, F$, The onset of the pathology, based on DARPP-32 immunoreactivity, is also significantly delayed with longer huntingtin fragments. A moderate loss of DARPP-32 staining is seen with the htt 853 vector, whereas limited neuropathology, with DARPP-32 staining still present in neuronal cell bodies is observed in htt1520-82Q-injected rats.

only a minor effect on the DARPP-32 staining, even at 6 months (Fig. 10).

\section{DISCUSSION}

In the present study, we demonstrated that lentiviral-mediated delivery of mutant huntingtin provides a new strategy for devel- oping animal models of HD. The local overexpression of htt fragments with expanded polyglutamine repeats induced a cascade of events with a progressive increase in the severity of the phenotype consistent with the human pathology.

In the first set of experiments, we used htt-expressing lentiviral vectors coding for the first 171 amino acids of the protein with 19 and $82 \mathrm{CAG}$ repeats. Immunohistochemical analysis indicated that transduced neurons overexpressing htt171 fragments are present in a large area of the striatum. In htt171-82Q-injected rats, intranuclear inclusions rapidly accumulate during the first 4 weeks. The EM48 staining, however, disappears from the center of the transduced area 8 and 12 weeks after injection, whereas the total number of N Is remains constant during that period. In situ hybridization and immunohistochemical analysis with an anti-htt antibody demonstrate that a gradient of expression is present in lentiviral-injected animals. These observations suggest that a striatal degeneration is occurring in these animals and that infected neurons expressing high levels of mutant huntingtin are first affected, whereas neurons located at the periphery of the infected zone and expressing a lower level of htt develop aggregates with slower kinetics. Decreasing the expression levels of mutant htt (CMV-htt171-82Q) significantly delayed the kinetics of appearance and the number of htt NIs and further supports this interpretation. A dose effect was also described in an adenoassociated virus-97Q-green fluorescent protein (GFP) study with cells expressing high levels of 97Q-GFP being eliminated more rapidly than cells expressing low levels of the mutant protein (Senut et al., 2000). In agreement with previous reports in transgenic mice and presymptomatic patients, we observed that aggregation occurs before ubiquitination (Mangiarini et al., 1996; Gomez-Tortosa et al., 2001; Lin et al., 2001).

Decreasing the expression of mutant htt affects not only the onset and severity of the pathology but also the subcellular localization of htt aggregates. Intranuclear inclusions and neuritic aggregates were observed in CMV-htt171-82Q-injected rats, whereas the aggregates were mainly located in the nucleus of PGK-htt171-82Q-infected cells. Previous studies have shown that both nuclear and neuritic aggregates are present in several htt transgenic mice (R6/2, N171-82Q, and Hdh ${ }^{\text {80CAG; }}$ Li et al., 1999; Schilling et al., 1999; Shelbourne et al., 1999). In R6/2 and $\mathrm{Hdh}^{80 \mathrm{CAG}}$ knock-in mice, the neuritic aggregates appear later than the intranuclear inclusions (Li et al., 1999; Schilling et al., 1999; Li et al., 2000). Finally, in HD patients, neuropil aggregates are prevalent in cortical and striatal neurons (DiFiglia et al., 1997). Our data raise the possibility that the formation of small and abundant aggregates in axons and dendrites is favored in cells expressing low levels of mutant huntingtin, whereas the development of nuclear inclusions is associated with the presence of high levels of htt.

The relative contribution of neuritic or nuclear aggregates or both to the disease process is unclear, and whether they play a role in the disease progression or, on the contrary, represent a detoxifying mechanism to sequester abnormal proteins is still debated (Sisodia, 1998). Recent in vitro findings suggest that the presence of NIs can be dissociated from neuronal cell death (Saudou et al., 1998; Evert et al., 1999; Kim et al., 1999). Discrepancies between the topographic distribution of NIs and the selective neuropathology of $\mathrm{HD}$, spinocerebellar ataxia type 2 (SCA2), SCA7, and spinobulbar muscular atrophy have also been reported (Holmberg et al., 1998; Li et al., 1998; Koyano et al., 1999; Kuemmerle et al., 1999). Finally, no significant neuronal degeneration was observed in several HD transgenic mice with 
numerous NIs, whereas others show mild striatal neurodegeneration with relatively few N Is (Mangiarini et al., 1996; Reddy et al., 1998; Hodgson et al., 1999; Schilling et al., 1999). Taken together, these data indicate that aggregation is a good indicator for the presence of abnormal conformation of htt and thus may be an indirect marker for a pathogenic process, but that these inclusions are not themselves necessarily causes of cell death.

Accumulating evidence suggests that neuronal dysfunction precedes striatal degeneration in HD. Magnetic resonance imaging, computed tomographic, and positron emission tomographic studies indicate that neuronal alterations are present before the appearance of clinical symptoms (Mazziotta et al., 1987; Grafton et al., 1990; Aylward et al., 1994, 2000; Antonini et al., 1996; Andrews et al., 1999). A decrease in DARPP-32 expression was, for example, observed in early symptomatic transgenic mice showing no obvious cell loss (Bibb et al., 2000; Luthi-Carter et al., 2000; Menalled et al., 2000; van Dellen et al., 2000). We have therefore used a DARPP-32 antibody to monitor the appearance of neuronal dysfunction in htt171-82Q-injected rats. In all cases, the loss of DARPP-32 immunoreactivity was delayed compared with the occurrence of nuclear inclusions. Beginning 4 weeks after injection, a DARPP-32-depleted region was observed around the injection site in the htt171-82Q-injected rats. At 1 month after injection, Fluoro-Jade B staining suggested that a neurodegenerative process accompanied the downregulation of DARPP-32 staining. At later time points, cresyl violet staining and the progressive shrinkage of the tissue clearly demonstrated that robust cell death occurred in htt171-82Q-injected rats.

Importantly, this degenerative process is not affecting all neuronal subpopulations. In agreement with the human disease, a selective sparing of ChAT and NADPH-d neurons was observed despite the presence of NIs in both neuronal populations (Ellison et al., 1987; Ferrante et al., 1987). Further studies are needed to determine whether all infected ChAT and NADPH-d neurons develop NIs or whether the frequency of aggregate formation is lower in these interneurons, as suggested by Kosinski et al. (1999). Our results also indicate that the expression of mutant htt in the striatum is sufficient to induce a neuropathology and a specific degeneration of GABAergic neurons. Lentiviralmediated delivery of mutant htt in the cortex should provide further information on the potential contribution of glutamatergic neurons in HD pathology.

In a second set of experiments, we showed that the onset of pathology is inversely correlated with the number of CAG repeats similarly to what has been observed in HD patients (Andrew et al., 1993; Craufurd and Dodge, 1993; Persichetti et al., 1995; Becher et al., 1998). At 3 months, no loss of DARPP-32 staining was observed with the htt171-44Q vector despite the presence of N Is in some of the infected neurons. This might be attributable to the limited time frame of analysis and the incomplete penetrance of the disease with short CAG expansion. In contrast, rats injected with the htt171-66Q vector showed the typical loss of DARPP-32 staining and a progressive accumulation of htt aggregates. As expected, the phenotype was milder than in htt171-82Qinjected animals.

Finally, a temporal and spatial analysis of the striatum revealed that the pathogenesis is modulated by htt protein length. The number of aggregates was significantly decreased in htt853-82Qand htt1520-82Q-injected rats compared with htt171-82Qinjected animals. This result is in agreement with previous in vitro studies (Lunkes and Mandel, 1998; Saudou et al., 1998; Karpuj et al., 1999). Moreover, the frequency of neuritic aggregates was

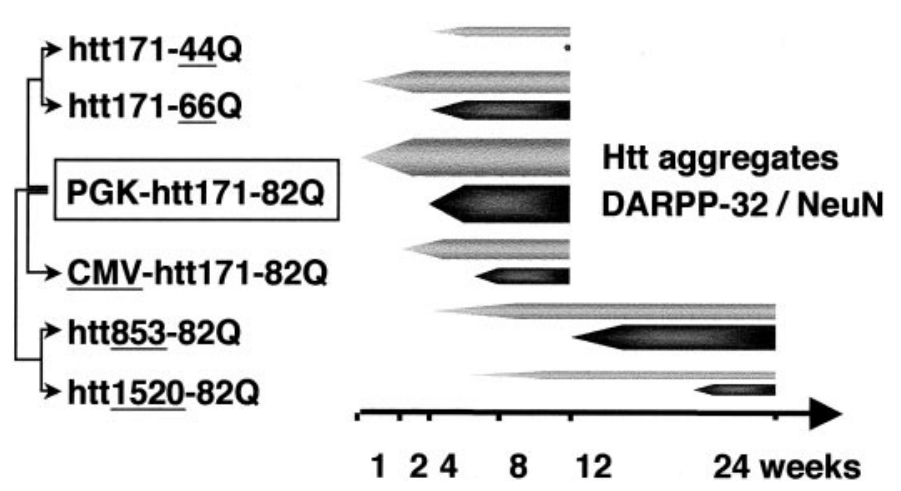

Figure 11. Diagram summarizing the neuropathologies observed with the various huntingtin-expressing lentiviral vectors. The arrows indicate the time points at which the initial pathological processes were observed based on huntingtin and DARPP-32 and NeuN immunoreactivity. The thickness of the arrows indicates the severity of the phenotype.

increased with the longer htt fragments. The phenomenon has also been observed in cells infected with amplicon vectors coding for various htt fragments (Martindale et al., 1998). The observation that the pathology is inversely proportional to the huntingtin protein size is consistent with the late onset phenotype observed in htt full-length YAC72 mice (Hodgson et al., 1999) and the early onset pathology of R6/2 htt exon 1 mice (Davies et al., 1997). Recent studies suggest that the full-length huntingtin protein may diminish the overall toxicity of polyglutamine repeats and may contain antiapoptotic domains (Rigamonti et al., 2000).

Although it was not our primary objective, we investigated whether the expression of mutant huntingtin in the rats caused apomorphine-induced rotation. None, however, showed behavioral impairments, suggesting that only multiple injections may lead to behavioral abnormalities.

In summary, these results demonstrate that lentiviral-mediated delivery of htt171-82Q but not htt171-19Q induces a pathology characterized by rapid appearance of neuritic or nuclear ubiquitinated huntingtin aggregates, or both, followed by neuronal dysfunction and astrogliosis, leading finally to robust and selective degeneration of striatal GABAergic neurons. In addition, a correlation was observed among polyglutamine repeat size, huntingtin protein length, expression levels and the onset and severity of the pathology (Fig. 11). Lentiviral-mediated injection of mutant htt may therefore provide a flexible setting to dissect the molecular mechanisms leading to the specific degeneration of medium spiny striatal neurons in vivo and to evaluate potential therapeutic molecules that may prevent or delay the onset of the disease.

\section{REFERENCES}

Andrew SE, Goldberg YP, Kremer B, Telenius H, Theilmann J, Adam S, Starr E, Squitieri F, Lin B, Kalchman MA, Graham RK, Hayden MR (1993) The relationship between trinucleotide (CAG) repeat length and clinical features of Huntington's disease. Nat Genet 4:398-403.

Andrews TC, Weeks RA, Turjanski N, Gunn RN, Watkins LH, Sahakian B, Hodges JR, Rosser AE, Wood NW, Brooks DJ (1999) Huntington's disease progression. PET and clinical observations. Brain 122:2353-2363.

Antonini A, Leenders KL, Spiegel R, Meier D, Vontobel P, WeigellWeber M, Sanchez-Pernaute R, de Yebenez JG, Boesiger P, Weindl A Maguire RP (1996) Striatal glucose metabolism and dopamine D2 receptor binding in asymptomatic gene carriers and patients with Huntington's disease. Brain 119:2085-2095.

Aylward EH, Brandt J, Codori AM, Mangus RS, Barta PE, Harris GJ (1994) Reduced basal ganglia volume associated with the gene for 
Huntington's disease in asymptomatic at-risk persons. Neurology 44:823-828.

Aylward EH, Codori AM, Rosenblatt A, Sherr M, Brandt J, Stine OC, Barta PE, Pearlson GD, Ross CA (2000) Rate of caudate atrophy in presymptomatic and symptomatic stages of Huntington's disease. Mov Disord 15:552-560.

Becher MW, Kotzuk JA, Sharp AH, Davies SW, Bates GP, Price DL, Ross CA (1998) Intranuclear neuronal inclusions in Huntington's disease and dentatorubral and pallidoluysian atrophy: correlation between the density of inclusions and IT15 CAG triplet repeat length. Neurobiol Dis 4:387-397.

Bibb JA, Yan Z, Svenningsson P, Snyder GL, Pieribone VA, Horiuchi A, Nairn AC, Messer A, Greengard P (2000) Severe deficiencies in dopamine signaling in presymptomatic Huntington's disease mice. Proc Natl Acad Sci USA 97:6809-6814.

Blömer U, Naldini L, Kafri T, Trono D, Verma IM, Gage FH (1997) Highly efficient and sustained gene transfer in adult neurons with a lentivirus vector. J Virol 71:6641-6649.

Cooper JK, Schilling G, Peters MF, Herring WJ, Sharp AH, Kaminsky Z, Masone J, Khan FA, Delanoy M, Borchelt DR, Dawson VL, Dawson TM, Ross CA (1998) Truncated N-terminal fragments of Huntingtin with expanded glutamine repeats form nuclear and cytoplasmic aggregates in cell culture. Hum Mol Genet 7:783-790.

Craufurd D, Dodge A (1993) Mutation size and age at onset in Huntington's disease. J Med Genet 30:1008-1011.

Davies SW, Turmaine M, Cozens BA, DiFiglia M, Sharp AH, Ross CA, Scherzinger E, Wanker EE, Mangiarini L, Bates GP (1997) Formation of neuronal intranuclear inclusions underlies the neurological dysfunction in mice transgenic for the HD mutation. Cell 90:537-548.

de Almeida PL, Zala D, Aebischer P, Déglon N (2001) Neuroprotective effect of a CNTF-expressing lentiviral vector in the quinolinic acid rat model of Huntington's disease. Neurobiol Dis 8:433-446.

Déglon N, Tseng JL, Bensadoun JC, Zurn AD, Arsenijevic Y, Pereira de Almeida L, Zufferey R, Trono D, Aebischer P (2000) Self-inactivating lentiviral vectors with enhanced transgene expression as potential gene transfer system in Parkinson's disease. Hum Gene Ther 11:179-190.

DiFiglia M, Sapp E, Chase KO, Davies SW, Bates GP, Vonsattel JP, Aronin N (1997) Aggregation of Huntingtin in neuronal intranuclear inclusions and dystrophic neurites in brain. Science 277:1990-1993.

Duyao M, Ambrose C, Myers R, Novelletto A, Persichetti F, Frontali M, Folstein S, Ross C, Franz M, Abbott M, Gray J, Conneally P, Young A, Penney J, Hollingsworth Z, Shoulson I, Lazzarini A, Falek A, Koroshetz W, Sax D, et al. (1993) Trinucleotide repeat length instability and age of onset in Huntington's disease. Nat Genet 4:387-392.

Ellison DW, Kowall NW, Martin JB (1987) Subset of neurons characterized by the presence of NADPH-diaphorase in human substantia innominata. J Comp Neurol 260:233-245.

Evert BO, Wüllner U, Schulz JB, Weller M, Groscurth P, Trottier Y, Brice A, Klockgether T (1999) High level expression of expanded full-length ataxin-3 in vitro causes cell death and formation of intranuclear inclusions in neuronal cells. Hum Mol Genet 8:1169-1176.

Ferrante RJ, Beal MF, Kowall NW, Richardson EP, Martin JB (1987) Sparing of acetylcholinesterase-containing striatal neurons in Huntington's disease. Brain Res 411:162-166.

Furtado S, Suchowersky O, Rewcasle NB, Graham L, Klimek ML, Garber A (1996) Relationship between trinucleotide repeats and neuropathological changes in Huntington's disease. Ann Neurol 39:132-136.

Gomez-Tortosa E, MacDonald ME, Friend JC, Taylor SA, Weiler LJ, Cupples LA, Srinidhi J, Gusella JF, Bird ED, Vonsattel JP, Myers RH (2001) Quantitative neuropathological changes in presymptomatic Huntington's disease. Ann Neurol 49:29-34.

Grafton ST, Mazziotta JC, Pahl JJ, St. George-Hyslop P, Haines JL, Gusella J, Hoffman JM, Baxter LR, Phelps ME (1990) A comparison of neurological, metabolic, structural, and genetic evaluations in persons at risk for Huntington's disease. Ann Neurol 28:614-621.

Greengard P, Allen PB, Naim AC (1999) Beyond the dopamine receptor: the DARPP-32/protein phosphatase-1 cascade. Neuron 23:435-447.

Hodgson JG, Agopyan N, Gutekunst C-A, Leavitt BR, LePiane F, Singaraja R, Smith DJ, Bissada N, McCutcheon K, Nasir J, Jamot L, Li X-J, Stevens ME, Rosemond E, Roder JC, Phillips AG, Rubin EM, Hersch SM, Hayden MR (1999) A YAC mouse model for Huntington's disease with full-length mutant huntingtin, cytoplasmic toxicity, and selective striatal neurodegeneration. Neuron 23:181-192.

Holmberg M, Duyckaerts C, Durr A, Cancel G, Gourfinkel-An I, Damier P, Faucheux B, Trottier Y, Hirsch EC, Agid Y, Brice A (1998) Spinocerebellar ataxia type 7 (SCA7): a neurodegenerative disorder with neuronal intranuclear inclusions. Hum Mol Genet 7:913-918.

Hottinger AF, Azzouz M, Déglon N, Aebischer P, Zurn AD (2000) Complete and long-term rescue of lesioned adult motoneurons by lentiviral-mediated expression of glial cell line-derived neurotrophic factor in the facial nucleus. J Neurosci 20:5587-5593.

Huntington's Disease Collaborative Research Group (1993) A novel gene containing a trinucleotide repeat that is expanded and unstable on Huntington's disease chromosome. Cell 72:971-983.
Hurlbert MS, Zhou W, Wasmeier C, Kaddis FG, Hutton JC, Freed CR (1999) Mice transgenic for an expanded CAG repeat in the Huntington's disease gene develop diabetes. Diabetes 48:649-651.

Kafri T, van Praag H, Gage FH, Verma IM (2000) Lentiviral vectors: regulated gene expression. Mol Ther 1:516-521.

Karpuj MV, Garren H, Slunt H, Price DL, Gusella J, Becher MW, Steinman L (1999) Transglutaminase aggregates huntingtin into nonamyloidogenic polymers, and its enzymatic activity increases in Huntington's disease brain nuclei. Proc Natl Acad Sci USA 96:7388-7393.

Kim M, Lee H-S, LaForet G, McIntyre C, Martin EJ, Chang P, Kim TW, Williams M, Reddy PH, Tagle D, Boyce FM, Won L, Heller A, Aronin N, DiFiglia M (1999) Mutant huntingtin expression in clonal striatal cells: dissociation of inclusion formation and neuronal survival by caspase inhibition. J Neurosci 19:963-973.

Kordower JH, Emborg ME, Bloch J, Ma SY, Chu Y, Leventhal L, McBride J, Chen EY, Palfi S, Roitberg BZ, Brown WD, Holden JE Pyzalski R, Taylor MD, Carvey P, Ling Z, Trono D, Hantraye P Déglon N, Aebischer P (2000) Neurodegeneration prevented by lentiviral vector delivery of GDNF in primate models of Parkinson's disease. Science 290:767-773.

Kosinski CM, Cha J-H, Young AB, Mangiarini L, Bates G, Schiefer J, Schwarz M (1999) Intranuclear inclusions in subtypes of striatal neurons in Huntington's disease transgenic mice. NeuroReport 10:3891-3896.

Koyano S, Uchihara T, Fujigasaki H, Nakamura A, Yagishita S, Iwabuchi K (1999) Neuronal intranuclear inclusions in spinocerebellar ataxia type 2: triple-labeling immunofluorescent study. Neurosci Lett 273:117-120.

Kuemmerle S, Gutekunst CA, Klein AM, Li XJ, Li SH, Beal MF, Hersch SM, Ferrante RJ (1999) Huntington aggregates may not predict neuronal death in Huntington's disease. Ann Neurol 46:842-849.

Li H, Li S-H, Cheng AL, Mangiarini L, Bates GP, Li X-J (1999) Ultrastructural localization and progressive formation of neuropil aggregates in Huntington's disease transgenic mice. Hum Mol Genet 8:1227-1236.

Li H, Li S-H, Johnston H, Shelbourne PF, Li X-J (2000) Amino-terminal fragments of mutant huntingtin show selective accumulation in striatal neurons and synaptic toxicity. Nat Genet 25:385-389.

Li M, Miwa S, Kobayashi Y, Merry DE, Yamamoto M, Tanaka F, Doyu M, Hashizume Y, Fischbeck KH, Sobue G (1998) Nuclear inclusions of the androgen receptor protein in spinal and bulbar muscular atrophy. Ann Neurol 44:249-254.

Lin CH, Tallaksen-Greene S, Chien WM, Cearley JA, Jackson WS, Crouse AB, Ren S, Li XJ, Albin RL, Detloff PJ (2001) Neurologica abnormalities in a knock-in mouse model of Huntington's disease. Hum Mol Genet 10:137-144.

Lunkes A, Mandel J-L (1998) A cellular model that recapitulates major pathogenic steps of Huntington's disease. Hum Mol Genet 7:1355-1361.

Luthi-Carter R, Strand A, Peters NL, Solano SM, Hollingsworth ZR, Menon AS, Frey AS, Spektor BS, Penney EB, Schilling G, Ross CA Borchelt DR, Tapscott SJ, Young AB, Cha JH, Olson JM (2000) Decreased expression of striatal signaling genes in a mouse model of Huntington's disease. Hum Mol Genet 9:1259-1271.

Mangiarini L, Sathasivam K, Seller M, Cozens B, Harper A, Hetherington C, Lawton M, Trottier Y, Lehrach H, Davies SW, Bates GP (1996) Exon 1 of the HD gene with an expanded CAG repeat is sufficient to cause a progressive neurological phenotype in transgenic mice. Cell 87:493-506.

Martindale D, Hackam A, Wieczorek A, Ellerby L, Wellington C, McCutcheon K, Singaraja R, Kazemi-Esfarjani P, Devon R, Kim SU, Bredesen DE, Tufaro F, Hayden MR (1998) Length of huntingtin and its polyglutamine tract influences localization and frequency of intracellular aggregates. Nat Genet 18:150-154.

Mazziotta JC, Phelps ME, Pahl JJ, Huang SC, Baxter LR, Riege WH Hoffman JM, Kuhl DE, Lanto AB, Wapenski JA, Markham CH (1987) Reduced cerebral glucose metabolism in asymptomatic subjects at risk for Huntington's disease. N Engl J Med 316:357-362.

Menalled L, Zanjani H, MacKenzie L, Koppel A, Carpenter E, Zeitlin S Chesselet MF (2000) Decrease in striatal enkephalin mRNA in mouse models of Huntington's disease. Exp Neurol 162:328-342.

Naldini L (1998) Lentiviruses as gene transfer agents for delivery to non-dividing cells. Curr Opin Biotechnol 9:457-463.

Naldini L, Blömer U, Gallay P, Ory D, Mulligan R, Gage FH, Verma IM, Trono D (1996) In vivo gene delivery and stable transduction of nondividing cells by a lentiviral vector. Science 272:263-267.

Ory DS, Neugeboren BA, Mulligan RC (1996) A stable human-derived packaging cell line for production of high titer retrovirus/vesicular stomatitis virus $\mathrm{G}$ pseudotypes. Proc Natl Acad Sci USA 93:11400-11406.

Ouimet CC, Langley-Gullion KC, Greengard P (1998) Quantitative immunocytochemistry of DARPP-32-expressing neurons in the rat caudatoputamen. Brain Res 808:8-12.

Paulson HL (2000) Toward an understanding of polyglutamine neurodegeneration. Brain Pathol 10:293-299. 
Persichetti F, Ambrose CM, Ge P, McNeil SM, Srinidhi J, Anderson MA, Jenkins B, Barnes GT, Duyao MP, Kanaley L, Wexler NS, Myers RH, Bird ED, Vonsattel J-P, MacDonald ME, Gusella JF (1995) Normal and expanded Huntington's disease gene alleles produce distinguishable proteins due to translation across the CAG repeat. Mol Med $1: 374-383$.

Reddy PH, Williams M, Charles V, Garrett L, Pike-Buchanan L, Whetsell WO, Miller G, Tagle DA (1998) Behavioral abnormalities and selective neuronal loss in HD transgenic mice expressing mutated fulllength HD cDNA. Nat Genet 20:198-202.

Reddy PH, Charles V, Williams M, Miller G, Whetsell Jr WO, Tagle DA (1999a) Transgenic mice expressing mutated full-length $H D$ cDNA: a paradigm for locomotor changes and selective neuronal loss in Huntington's disease. Philos Trans R Soc Lond B Biol Sci 354:1035-1045.

Reddy PH, Williams M, Tagle DA (1999b) Recent advances in understanding the pathogenesis of Huntington's disease. Trends Neurosci 22:248-255.

Reynolds DS, Carter RJ, Morton AJ (1998) Dopamine modulates the susceptibility of striatal neurons to 3-nitropropionic acid in the rat model of Huntington's disease. J Neurosci 18:10116-10127.

Rigamonti D, Bauer JH, De-Fraja C, Conti L, Sipione S, Sciorati C, Clementi E, Hackam A, Hayden MR, Li Y, Cooper JK, Ross CA, Govoni S, Vincenz C, Cattaneo E (2000) Wild-type huntingtin protects from apoptosis upstream of caspase-3. J Neurosci 20:3705-3713.

Saudou F, Finkbeiner S, Devys D, Greenberg ME (1998) Huntingtin acts in the nucleus to induce apoptosis but death does not correlate with the formation of intranuclear inclusions. Cell 95:55-66.

Schilling G, Becher MW, Sharp AH, Jinnah HA, Duan K, Kotzuk JA, Slunt HH, Ratovitski T, Cooper JK, Jenkins NA, Copeland NG, Price DL, Ross CA, Borchelt DR (1999) Intranuclear inclusions and neuritic aggregates in transgenic mice expressing a mutant N-terminal fragment of huntingtin. Hum Mol Genet 8:397-407.

Schilling G, Jinnah HA, Gonzales V, Coonfield ML, Kim Y, Wood JD, Price DL, Li XJ, Jenkins N, Copeland N, Moran T, Ross CA, Borchelt DR. (2001) Distinct behavioral and neuropathological abnormalities in transgenic mouse models of HD and DRPLA. Neurobiol Dis 8:405-418.

Schmued LC, Hopkins KJ (2000) Fluoro-Jade B: a high affinity fluorescent marker for the localization of neuronal degeneration. Brain Res 874:123-130.
Schmued LC, Albertson C, Slikker W (1997) Fluoro-Jade: a novel fluorochrome for the sensitive and reliable histochemical localization of neuronal degeneration. Brain Res 751:37-46.

Senut M-C, Suhr ST, Kaspar B, Gage FH (2000) Intraneuronal aggregate formation and cell death after viral expression of expanded polyglutamine tracts in the adult rat brain. J Neurosci 20:219-229.

Shelbourne PF, Killeen N, Hevner RF, Johnston HM, Tecott L, Lewandoski M, Ennis M, Ramirez L, Li Z, Iannicola C, Littman DR, Myers RM (1999) A Huntington's disease CAG expansion at the murine Hdh locus is unstable and associated with behavioral abnormalities in mice. Hum Mol Genet 8:763-774.

Sisodia SS (1998) Nuclear inclusions in glutamine repeat disorders: are they pernicious, coincidental, or beneficial? Cell 95:1-4.

Snell RG, MacMillan JC, Cheadle JP, Fenton I, Lazarou LP, Davies P, MacDonald ME, Gusella JF, Harper PS, Shaw DJ (1993) Relantionship between trinucleotide repeat expansion and phenotypic variation in Huntington's disease. Nat Genet 4:393-397.

van Dellen A, Welch J, Dixon RM, Cordery P, York D, Styles P, Blakemore C, Hannan AJ (2000) N-Acetylaspartate and DARPP-32 levels decrease in the corpus striatum of Huntington's disease mice. NeuroReport 11:3751-3757.

Vonsattel JP, DiFiglia M (1998) Huntington disease. J Neuropathol Exp Neurol 57:369-384.

Wheeler VC, Auerbach W, White JK, Srinidhi J, Auerbach A, Ryan A, Duyao MP, Vrbanac V, Weaver M, Gusella JF, Joyner AL, MacDonald ME (1999) Length-dependent gametic CAG repeat instability in the Huntington's disease knock-in mouse. Hum Mol Genet 8:115-122.

White JK, Auerbach W, Duyao MP, Vonsattel J-P, Gusella JF, Joyner AL, MacDonald ME (1997) Huntingtin is required for neurogenesis and is not impaired by the Huntington's disease CAG expansion. Nat Genet 17:404-410.

Wilkinson FL, thi Man N, Manilal SB, Thomas P, Neal JW, Harper PS, Jones AL, Morris GE. (1999) Localization of rabbit huntingtin using a new panel of monoclonal antibodies. Brain Res Mol Brain Res 69:10-20.

Yamamoto A, Lucas JJ, Hen R (2000) Reversal of neuropathology and motor dysfunction in a conditional model of Huntington's disease. Cell 101:57-66. 